\title{
Experiment Research on the Mechanical Property of Micron Particles Filled Silicone Rubber Material
}

\author{
Chen Xiong ${ }^{1}$, Wang Hongli ${ }^{1}$, Xu Jinsheng ${ }^{*}, 1$ and Zhao Lei ${ }^{2}$ \\ ${ }^{1}$ School of Mechanical Engineering, Nanjing University of Science and Technology, Nanjing 210094, China \\ ${ }^{2}$ State-Operated 9324 Factories, Hefei 230000, China
}

\begin{abstract}
Six kinds of different content of micron solid particles of silicone rubber materials were prepared by mixing micron $\mathrm{Al}_{2} \mathrm{O}_{3}, \mathrm{SiO}_{2}$, cross-linking agent, and catalyst, etc. into the matrix material of micron-sized hydroxyl-terminated polydimethylsiloxane. The effect of micron solid particles on the mechanical property of silicone rubber was examined by the uniaxial tensile tests. Non-contact strain test system was adopted to measure the strain response of the samples in the experiments. The results show that, the mechanical property of silicone rubber material is rate-dependent, presenting a hyper-elastic property, which is similar to rubber-like material. The strength of the granular filled material increased with the content of the solid particles, moreover, the enhancement effect caused by $\mathrm{SiO}_{2}$ was stronger than that caused by $\mathrm{Al}_{2} \mathrm{O}_{3}$.
\end{abstract}

Keywords: Silicone rubber, mechanical property, uniaxial tension, rate-dependence, breaking strength.

\section{INTRODUCTION}

Silicone rubber is one of the little smoke thermal protection materials which has been generally researched in the field of aeronautics and astronautics because of favorable properties of thermal stability, high temperature resistance and aging resistance [1]. In the $28^{\text {th }}$ joint propulsion conference held by AIAA, it was mentioned that polydimethylsiloxane is likely to be the next generation of thermal protection material [2]. Recently, studies on silicone rubber mainly focused on the material prescription, ablation property and aging property. Research results show that the mechanical property of the thermal protection material is worth studying under the environmental loading and high temperature gas brush [3]. However, there are still many deficiencies in the studies analyzing mechanical property of silicone rubber, especially the micron particles filled silicone rubber. Therefore, it is necessary to conduct a detailed study on the mechanical property of silicone rubber material.

To lucubrate the mechanical property of silicone rubber material, Kwan [4] studied the rubber reinforcing effect of $\mathrm{SiO}_{2}$ produced by sol-gel method, and the results show that different elastic modulus and hardness of silicone rubber material can be obtained through adjusting the proportion of ethylene content and solid particle content. Meunier [5] conducted a series of tensile tests, pure shear tests and compression tests on silicone rubber material without any fillers in it. Five kinds of hyper-elastic models were used to compare the experimental results, and the Mullins effect, hysteresis and rate-dependence were ignored in the

*Address correspondence to this author at the School of Mechanical Engineering, Nanjing University of Science and Technology, Nanjing, Jiangsu, 210094, China; Tel: 13913884552 ;

E-mail: chenxiong@njust.edu.cn study. Xu [6] studied the mechanical property of silicone rubber material with different contents of ethylene and found that the material has viscoelastic properties. The glass transition temperature of the material was obtained by dynamic mechanical analysis (DMA) technology. Korochkina [7] adopted experimental and numerical methods to study the applicability of constitutive models of silicone rubber. Yingwen Zhou et al. [8] discussed the influence of micron- sized particle with a diameter of $\mathrm{Al}_{2} \mathrm{O}_{3}$ and the filled level on the mechanical property of silicone rubber, where the mechanical property was used to compare with the nano-sized $\mathrm{Al}_{2} \mathrm{O}_{3}$ filled material. Liu Jun et al. [9] studied the effect of different kinds and amount of coupling agents on the mechanical property of silicone rubber material, and observed the microscopic structure of colloid section by using the electron microscopy. Wenying Zhou et al. [10] studied the effects of the amount, particle size, and mixing mass ratio of the hybrid alumina filler particles on the thermal conductivity and mechanical properties of silicone rubber. Luheng Wang [11] studied the compressive resistance relaxation of black carbon filled with silicone rubber composite, and the results show that at the stage of the compressive stress relaxation, the composite resistance and the stress both can be adjusted by the linear combination of three negative exponential functions. Yoshimura et al. [12] researched the electrical and mechanical properties of the silicone-rubber composites formed by spring-shaped carbon microcoils (CMCs) embedded in silicone-rubber. Results show that with a compressive or tensile strain, the resistivity increased more greatly than any of the other composites.

According to the above review, researchers have studied the effect of content and the kind of filler on the mechanical property of silicone rubber material, and further studied the constitutive model of this kind of material, which lay a 
theoretical foundation for the application of the material. However, the theoretical study was still in a fledging period, and needs to be further developed. Here, hydroxylterminated polydimethylsiloxane (silicone rubber) was taken as the matrix material, and the influence of micron $\mathrm{SiO}_{2}$ and $\mathrm{Al}_{2} \mathrm{O}_{3}$ particles on the mechanical property were studied, laying the foundation for the constitutive model of particlefilled silicone rubber material.

\section{PREPARATION OF MATERIALS AND SPECIMENS}

The silicon rubber with thermal protection material used in this experiment was made up of silicone rubber (107, Beijing Chem. Plant, China) as the matrix [11], $\mathrm{Al}_{2} \mathrm{O}_{3}$ with 5 microns particle size, $\mathrm{SiO}_{2}$ with 3 microns particle size, cross-linking agent and catalyst. The diameters of all the micron solid particles were around 20 micron. The equipment used in the preparation of the material included: vacuum chamber, mixer, beaker, medical syringe and homemade mould. Raw materials required include: matrix material (silicone rubber), catalyst (dibutyltin dilaurate), cross-linking agent (tetraethoxysilane), mold release agent (methyl silicone oil) and filler materials (micron $\mathrm{Al}_{2} \mathrm{O}_{3}$ and $\mathrm{SiO}_{2}$ particles). The process of material preparation can be divided into the following five steps:

(1) Mix fillers into matrix (silicone rubber) in a beaker and stir with a speed of 300-400 rpm for 10 minutes, to obtain a mixed rubber that has uniformity and stable performance

(2) Add some cross-linking agent and catalyst in the mixed rubber, and continue stirring with the speed of 300-400 rpm for 15 minutes;

(3) Put the mixture into the vacuum chamber for 20 minutes;

(4) Inject the cure rubber into the mold, and then keep the mixed material in the vacuum chamber for three hours again (methyl silicone oil is used as mold release agent);

(5) Keep the mixed material for seven days at room temperature after the inner bubbles disappear.

Micron particles filled silicone rubber materials with different mechanical property were obtained based on different content of micron particles in matrix, while keeping the technological parameters consistent. Different silicone rubber materials were used including Mass proportion of micron $\mathrm{Al}_{2} \mathrm{O}_{3}$ particles filled in the matrix was $10 \%, 20 \%$ and $30 \%$. These materials were used to study the effect of micron $\mathrm{Al}_{2} \mathrm{O}_{3}$ particles on the mechanical property of silicone rubber material. (2) The proportion of micron $\mathrm{SiO}_{2}$ particles filled in the mixture with $10 \%$ micron $\mathrm{Al}_{2} \mathrm{O}_{3}$ particles was $2 \%, 4 \%$ and $6 \%$. These materials were used to study the effect of micron $\mathrm{SiO}_{2}$ particles on the mechanical property of micron particles-filled silicone rubber material.

\section{EXPERIMENT STUDY}

\subsection{Experiment}

QJ-211B electronic universal testing machine (EUTM) and incubator were used to conduct the experiment; the temperature was $20^{\circ} \mathrm{C} \pm 2^{\circ} \mathrm{C}$, and humidity was $50 \% \pm 2 \%$, due to the limited range of the EUTM's force sensor of $20000 \mathrm{~N}$, which is significantly larger than the tensile strength of silicone rubber. In order to avoid large system error induced by the sensor, a sensor with a range of $200 \mathrm{~N}$ was used to measure the mechanical response.

Table 1. Silicone rubber materials with different content of micron solid particles.

\begin{tabular}{|c|c|c|}
\hline Material & $\mathbf{A l}_{\mathbf{2}} \mathbf{O}_{3}$ & $\mathbf{S i O}_{\mathbf{2}}$ \\
\hline \hline silicone rubber 1 & $10 \%$ & $0 \%$ \\
\hline silicone rubber 2 & $20 \%$ & $0 \%$ \\
\hline silicone rubber 3 & $30 \%$ & $0 \%$ \\
\hline silicone rubber 4 & $10 \%$ & $2 \%$ \\
\hline silicone rubber 5 & $10 \%$ & $4 \%$ \\
\hline silicone rubber 6 & $10 \%$ & $6 \%$ \\
\hline
\end{tabular}

The design of specimens was considered according to the slab construction characteristic of the prepared silicone rubber. The gauge length of the specimen was $50 \mathrm{~mm}$. Glue was used on each end of the specimen to adhere with aluminum joints, to construct the dumbbell tensile specimen [12] according to the aerospace industry standard of PRC, QJ 924-85. This kind of design can avoid relative slip between the specimens and chucks of testing machine and ensure the gauge length of the specimen is $50 \mathrm{~mm}$ (Fig. 1).
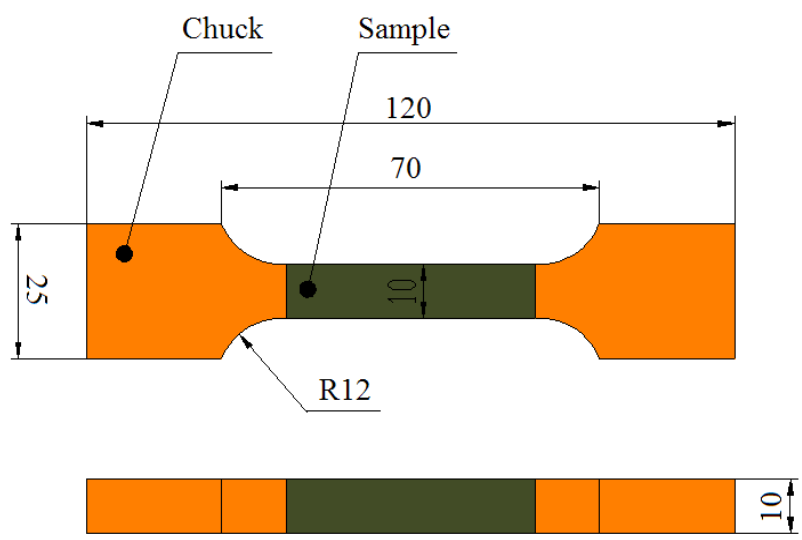

Fig. (1). Tensile specimen of micron particles filled silicone rubber material.

Non-contact test method was used to measure the strain response in the experiments. The system was mainly used to analyze the specklegram of sample surface filmed by CCD and automatically and quickly analyze the displacement and strain of the complete field, as shown in Fig. (2).

In order to study the rate-dependent mechanical property of the micron particles-filled materials, the stretching speeds of EUTM were set as $5 \mathrm{~mm} / \mathrm{min}, 50 \mathrm{~mm} / \mathrm{min}$ and 500 $\mathrm{mm} / \mathrm{min}$.

\subsection{Data Processing}

Experiments under each loading condition were repeated many times, and 3 effective results were selected to obtain 
the average results as the final experimental curve. Taking micron particles-filled silicone rubber 1 for example, three $\varepsilon$ - $t$ effective curves for $50 \mathrm{~mm} / \mathrm{min}$ tensile speed can be obtained, and the strain response measured by non-contact test system is shown in Fig. (3).

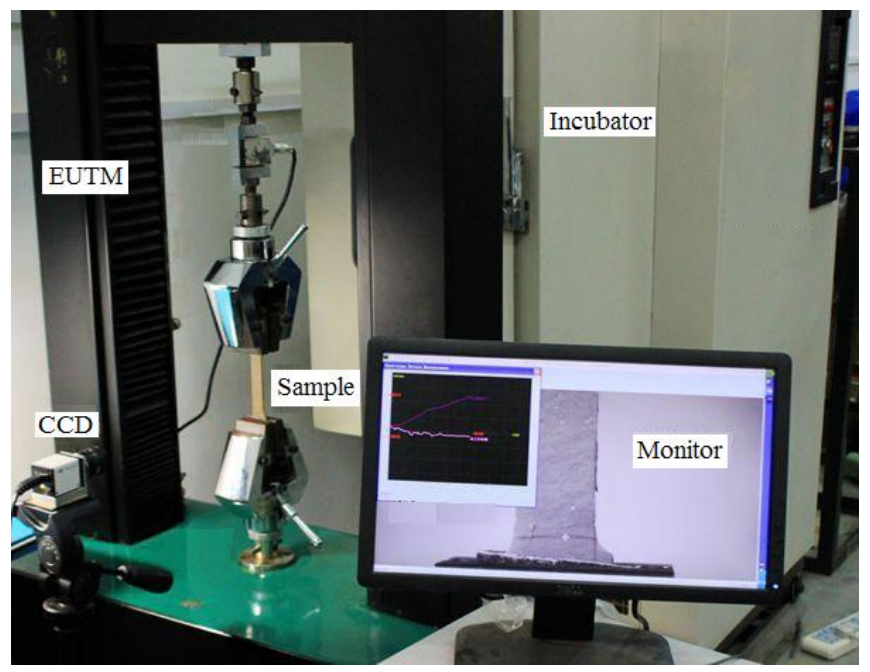

Fig. (2). Progress of non-contact strain test.

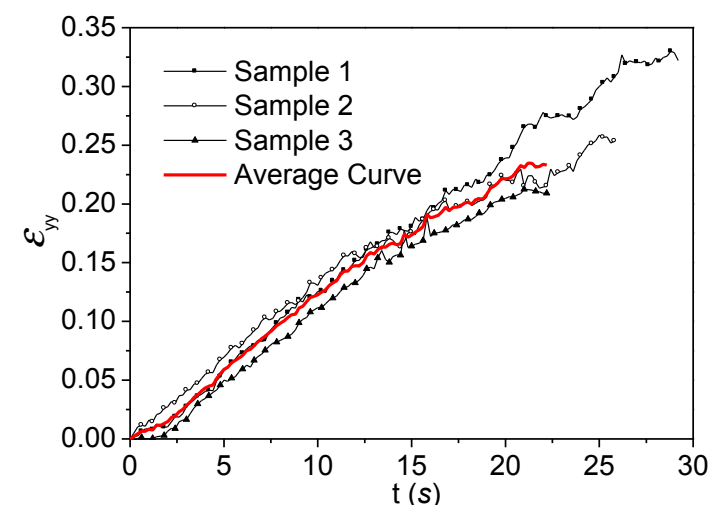

Fig. (3). Strain response measured by non-contact test system (50 $\mathrm{mm} / \mathrm{min})$.

As shown in Fig. (3), the strain rate of the specimens mainly obeyed the linear characteristic which is similar to the constant tensile speed $(50 \mathrm{~mm} / \mathrm{min})$, which illustrates that the stress-strain response of the silicone rubber 1 under constant strain rate can be obtained, and constant stretching rate can be calculated by fitting the $\varepsilon-t$ average curve. The strain rate is $0.011 \mathrm{~s}^{-1}(50 \mathrm{~mm} / \mathrm{min})$. Thus, the $\sigma-\varepsilon$ response can also be obtained by combining the constant strain rate value with the $\sigma$ - $t$ curves measured by force sensor. The actual constant strain rate for $5 \mathrm{~mm} / \mathrm{min}$ and $500 \mathrm{~mm} / \mathrm{min}$ are $0.00146 \mathrm{~s}^{-1}$ and $0.1 \mathrm{~s}^{-1}$ obtained by the same method, respectively.

Five $\sigma-\varepsilon$ curves of silicone rubber 1 with a tension of 50 $\mathrm{mm} / \mathrm{min}$ are shown in Fig. (4). It can be found that the stressstrain characteristics of the material are similar to each other, but the scattered error of elongations is larger

. The cause of these problems includes:

a) Debonding between the particles and the matrix occur in the particle-filled materials under certain loading, as shown in Fig. (5), with different scattered errors in the mechanical property due to different particle shape, size and orientation.

b) Cure conditions were different with the different location of cure mold during the preparation of the material, leading to the different mechanical property of the silicone rubber material.

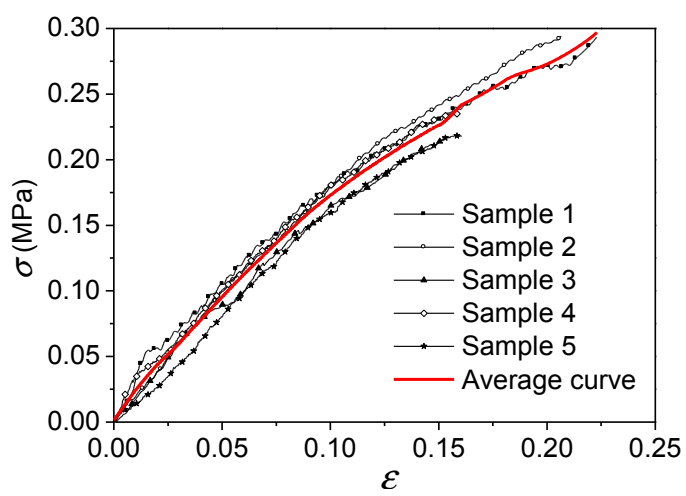

Fig. (4). $\sigma-\varepsilon$ Curves $(50 \mathrm{~mm} / \mathrm{min})$.

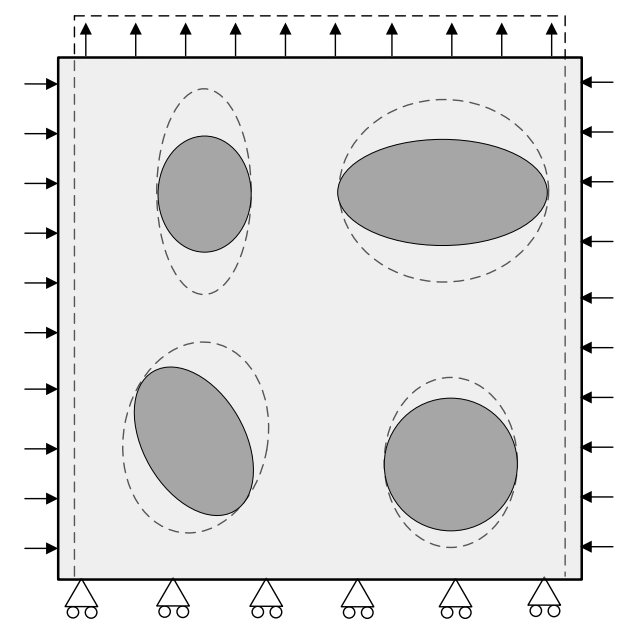

Fig. (5). Matrix filled with particles.

\section{RESULTS ANALYSIS AND DISCUSSION}

\subsection{Effect of Strain Rate on Mechanical Property}

According to the data processing method mentioned above, stress-strain responses of micron particles-filled silicone rubber material were obtained under all loading conditions. Here, the influence of strain rate, micron $\mathrm{Al}_{2} \mathrm{O}_{3}$ content and micron $\mathrm{SiO}_{2}$ content on the mechanical property of the material wasanalyzed.

The test results of silicone rubber 1 and silicone rubber 4 are given in Fig. (6). It can be found that the mechanical property of micron solid particles-filled silicone rubber was similar to the matrix material, which is rate-dependent, and depends on the time and loading history, belonging to a typical viscoelastic mechanic property. Tensile strength significantly increased with the increased tensile rate, which is associated to viscosity characteristics of the matrix material. Elongation also ultimately increased with increased strain rate. However, the inverse change law shown in Fig. (6b), was observed due to the scattered errors in the mechanical property induced by micron solid particles. 
Micron solid particles-filled silicone rubber materials in Table 1 have good elastic property and their maximum elongation is more than $25 \%$. Furthermore, the materials showed hysteresis characteristics during unloading, as the strain returned to the initial state gradually after 30 minutes, which can be described by a visco-hyper-elastic constitutive model as the rubber-like material. Thus, micron solid particles-filled silicone rubber belongs to the polymer having both hyper-elastic and viscoelastic properties. In few micron particles-filled materials, a similar behavior has been reported [13-15]. For better application in the field of engineering, the mechanical property of the material should be researched in detail.

(a) Silicone Rubber $1\left(10 \% \mathrm{Al}_{2} \mathrm{O}_{3}\right)$

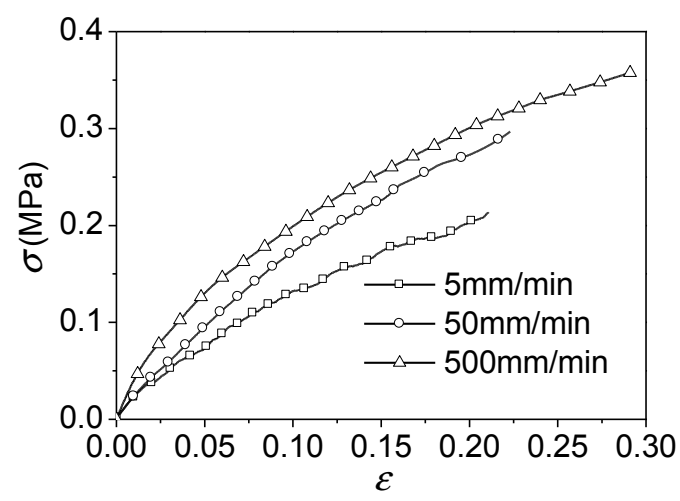

(b) Silicone Rubber $4\left(10 \% \mathrm{Al}_{2} \mathrm{O}_{3}+2 \% \mathrm{SiO}_{2}\right)$

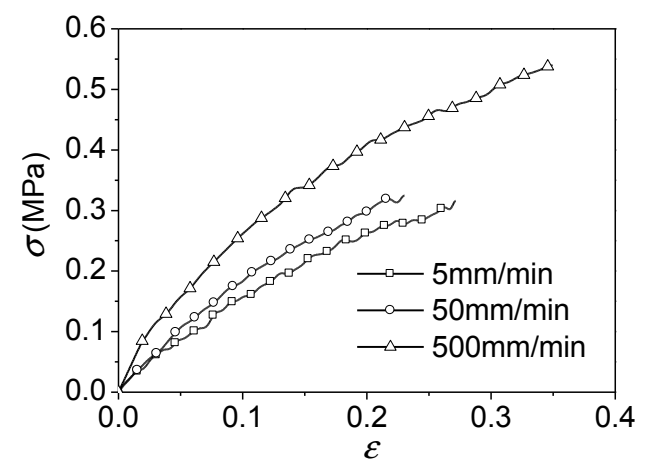

Fig. (6). $\sigma-\varepsilon$ curves for different loading conditions.

\subsection{Effect of Micron Solid Particles Proportion on Mechanical Property}

The comparisons of mechanical property induced by different contents of micron $\mathrm{Al}_{2} \mathrm{O}_{3}$ and $\mathrm{SiO}_{2}$ particles are shown in Fig. (7). The tensile strength of the material increased with the content of micron solid particles with any tensile speed. However, the maximum elongation showed large scattered errors and lack of regularity. This was due to lots of solid particles with high strength distributed in the silicone rubber matrix. The matrix was divided into many discontinuous matrix segments along the loading direction, as shown in Fig. (8), to increase the modulus of the matrix segments, resulting in increasing the materials' tensile strength along with the content of solid particles. This mechanical property is similar to the property of a spring, and it can be said that the modulus of a spring increased with the decrease in the spring's length. (a) $\mathrm{Al}_{2} \mathrm{O}_{3}$

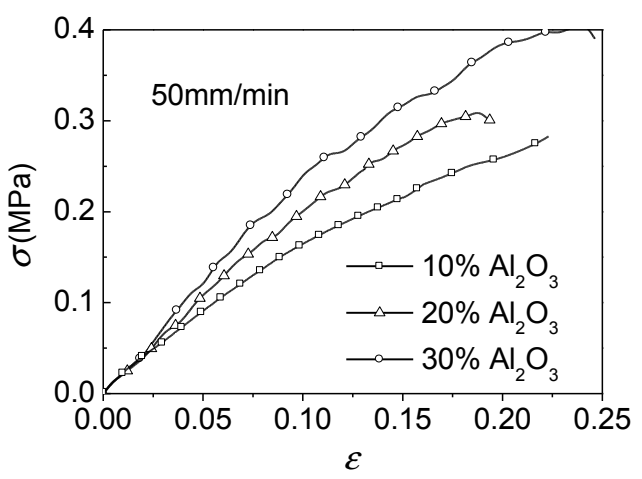

(b) $\mathrm{SiO}_{2}$

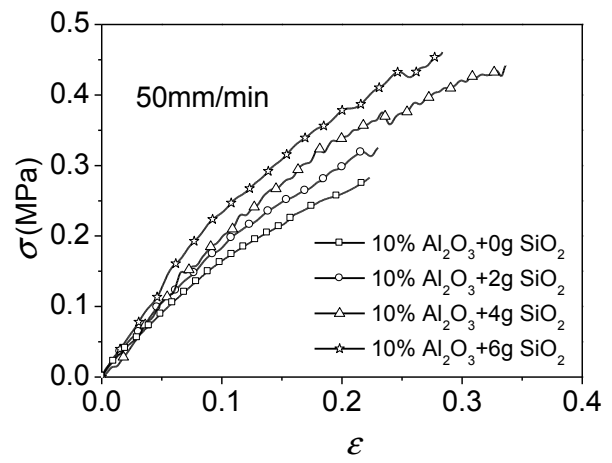

Fig. (7). Effect of micron solid particles' content on the mechanical property.

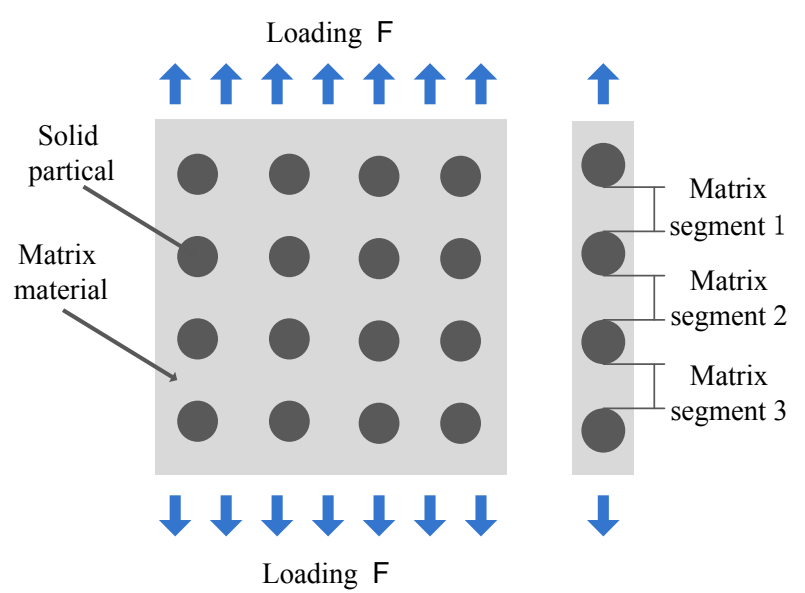

Fig. (8). Microstructure of micron particle filled material.

In Fig. (9), the tensile strength of six kinds of micron solid particles-filled silicone rubber was considered to make comparison with each other. It can be observed that micron $\mathrm{Al}_{2} \mathrm{O}_{3}$ and $\mathrm{SiO}_{2}$ particles increased the elastic modulus of micron solid particles-filled silicone rubber at a certain degree, while the enhancement effect of micron $\mathrm{Al}_{2} \mathrm{O}_{3}$ was significantly less than that of micron $\mathrm{SiO}_{2}$. This was because the particle size of micron $\mathrm{Al}_{2} \mathrm{O}_{3}$ was greater than that of micron $\mathrm{SiO}_{2}$, then the content of micron $\mathrm{SiO}_{2}$ particles was more than the content of micron $\mathrm{Al}_{2} \mathrm{O}_{3}$ per unit volume. According to the hypotheses represented in Fig. (8), the matrix segments were divided micron $\mathrm{SiO}_{2}$ particles are more than matrix segments cut by micron $\mathrm{Al}_{2} \mathrm{O}_{3}$ particles, so the enhancement effect of micron $\mathrm{SiO}_{2}$ particles is greater than that of micron $\mathrm{Al}_{2} \mathrm{O}_{3}$ particles. 


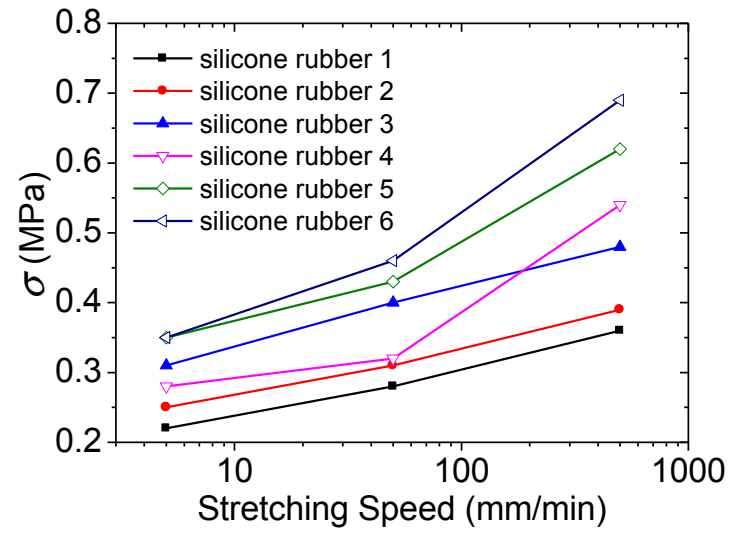

Fig. (9). Tensile strength of the materials with different content of micron solid particles.

To sum up, the mechanical property of micron solid particles-filled silicone rubber was observed to be largely rate- dependent, and the scattered errors in the elongations were larger. This phenomenon reflects that the ratedependent mechanical property of micron solid particlesfilled silicone rubber which is mainly due to the property of matrix material, and micron solid particles increased the modulus of the matrix. Moreover, the instability of bonding performance between micron particle surface and matrix led to the bigger difference in the elongation of the material.

\section{RATE-DEPENDENT STRENGTH CRITERION}

\subsection{Strength Criterion}

The octahedral shear strain failure criterion has been widely applied to polymers, i.e.

$\gamma_{8} \leq \frac{\gamma_{8 m}}{n}$

where $\gamma_{8 m}$ is the critical value, and $n$ is the safety coefficient. The octahedral shear strain can be expressed as:

$\gamma_{8}=\frac{1}{3} \sqrt{\left(\varepsilon_{1}-\varepsilon_{2}\right)^{2}+\left(\varepsilon_{2}-\varepsilon_{3}\right)^{2}+\left(\varepsilon_{3}-\varepsilon_{1}\right)^{2}}$

where $\varepsilon_{1}, \varepsilon_{2}$ and $\varepsilon_{3}$ are the principal strains. Under uniaxial tension, $\varepsilon_{2}=\varepsilon_{3}=-\mu \varepsilon_{1}, \mu$ is the poisson's ratio, then $\gamma_{8 m}$ can be expressed as the function of the largest elongation $\varepsilon_{m}$

$\gamma_{8 m}=\frac{\sqrt{2}}{3}(1+\mu) \varepsilon_{m}$

Mises equivalent strain can be described as:

$\varepsilon_{e}=\frac{\sqrt{2}}{3} \sqrt{\left(\varepsilon_{1}-\varepsilon_{2}\right)^{2}+\left(\varepsilon_{2}-\varepsilon_{3}\right)^{2}+\left(\varepsilon_{3}-\varepsilon_{1}\right)^{2}}$

where $\varepsilon_{e}$ is the equivalent strain. Under uniaxial tension, the relationship between the critical value $\varepsilon_{e m}$ and the largest elongation $\varepsilon_{e}$ can be described as:

$\varepsilon_{e m}=\frac{2}{3}(1+\mu) \varepsilon_{m}$

Thus, the octahedral shear strain $\gamma_{8}$ and Mises equivalent strain $\varepsilon_{e}$ have the following relationship: $\varepsilon_{e}=\sqrt{2} \gamma_{8}$

It is shown that the Mises equivalent strain criterion and octahedral shear strain criterion were essentially equivalent. Micron solid particles-filled silicone rubber can be seen as incompressible materials, as the $\mathrm{P}$ oisson's ratio is usually between $0.49 \sim 0.499$, thus making the maximum Mises strain approximately equal to the largest elongation $\varepsilon_{m}$ according to Eq.(5). Therefore, the largest elongation was used as the failure criteria of micron solid particles-filled silicone rubber specimen in this paper.

Similarly, for micron solid particles-filled silicone rubber, Mises equivalent stress can be expressed as:

$\sigma_{e}=\frac{\sqrt{2}}{2} \sqrt{\left(\sigma_{1}-\sigma_{2}\right)^{2}+\left(\sigma_{2}-\sigma_{3}\right)^{2}+\left(\sigma_{3}-\sigma_{1}\right)^{2}}$

Under uniaxial loading condition, $\sigma_{e}=\sigma_{1}$.

Thus, under uniaxial loading condition, the largest elongation and the tensile strength of the specimen can be directly used as the material's failure criterion.

\subsection{Rate-Correlated Strength Criterion}

According to the mechanical test results of micron solid particles-filled silicone rubber. shown in Fig. (9), the tension strength of the micron solid particles-filled silicone rubber showed a nearly linear relationship with the logarithmic value of strain rate except in some special testing condition. Thus, the strength criterion of the material can be defined as:

$$
\begin{aligned}
\sigma_{\max }= & \sigma_{0}\left[1+\phi(\mathrm{V}) \log V / 5+\phi\left(\mathrm{Al}_{2} \mathrm{O}_{3}\right)\left(\mathrm{Al}_{2} \mathrm{O}_{3} \%-10 \%\right)\right. \\
& \left.+\phi\left(\mathrm{SiO}_{2}\right) \mathrm{SiO}_{2} \%\right]
\end{aligned}
$$

where $\sigma_{0}=0.22 \mathrm{MPa}$ is the tensile strength of micron solid particles-filled silicon rubber 1 under $5 \mathrm{~mm} / \mathrm{min}$ tensile speed; $\varphi(V)$ is the impact factor of tensile speed; $\varphi\left(\mathrm{Al}_{2} \mathrm{O}_{3}\right)$ is the impact factor of micron $\mathrm{Al}_{2} \mathrm{O}_{3}$ particles; and $\varphi\left(\mathrm{SiO}_{2}\right)$ is the impact factor of micron $\mathrm{SiO}_{2}$ particles.

The impacts of micron solid particles and strain rate on the mechanical property of materials were emphatically analyzed as shown below. The strength value $(0.22 \mathrm{MPa})$ of micron solid particles-filled silicone rubber 1 was taken under $5 \mathrm{~mm} / \mathrm{min}$ tensile speed as the standard, based on the un-dimensioned process of material strength to calculate the impact factors of particles and tensile speed. :

(1) The strength values under all test conditions divided the value of $0.22 \mathrm{MPa}$ to be non-dimensionalized.

(2) For the silicone rubber 1, the increase in the ratio of strength with the increase of tensile speed (logarithmic value) was calculated;

(3) Step (2) was repeated until all silicone rubbers were processed;

(4) Similar to step (2), the increase in the ratio of strength with the increase in the particles' content was calculated.

The impact factors of tensile speed and micron particles' content influencing the mechanical property of the materials are shown in Fig. (10). Three impact factors $\varphi(V), \varphi\left(\mathrm{Al}_{2} \mathrm{O}_{3}\right)$ 
and $\varphi\left(\mathrm{SiO}_{2}\right)$ under different load conditions were obtained from Fig. (10); the average values of these parameters were taken as the final values as $0.25,2.5$ and 20.45 , respectively. To verify the accuracy of the model given in Eq. (7), the predicting tensile strength of silicone rubber 1 and silicone rubber 3 was compared with the test results as shown in Fig. (11).

(a) Impact Law of Tensile Speed

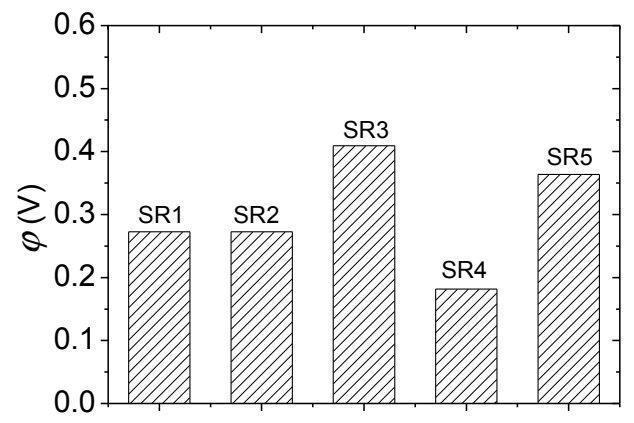

(b) Impact Law of Micron $\mathrm{Al}_{2} \mathrm{O}_{3}$ Particles' Content

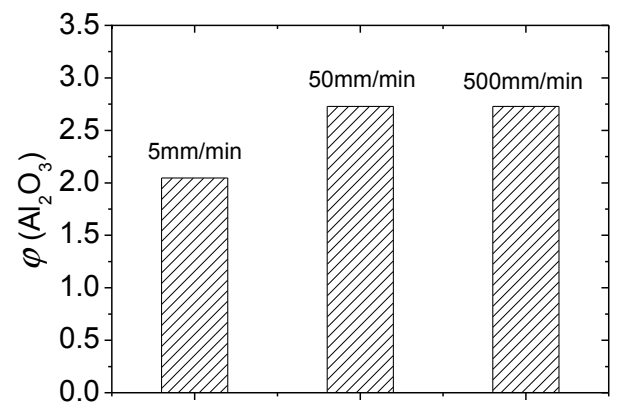

(c) Impact Law of Micron $\mathrm{SiO}_{2}$ Particles' Content

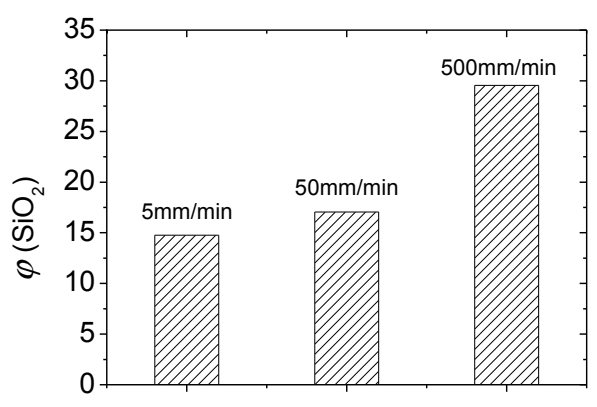

Fig. (10). Impact factor of tensile speed and micron particles' content.

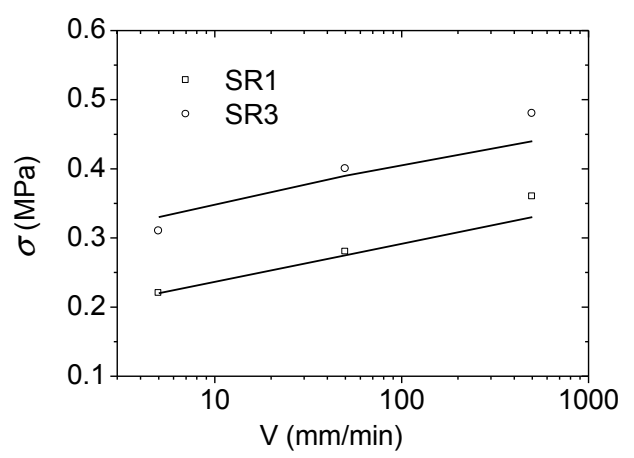

Fig. (11). Tensile strength verification of silicone rubber 1 and silicone rubber 3 .
In Fig. (11), the model qualitatively describes the influence of the speed of tensile and micron particles' content on the tensile strength of the micron particles-filled silicone rubber materials, but there are still some limitations. In future, the experimental conditions of micron particlesfilled rubber material should be extended to reduce the experimental errors by increasing the repetition number for the same loading condition.

\section{CONCLUSION}

Six kinds of micron solid particles-filled silicone rubber materials were prepared by mixing different content of micron $\mathrm{Al}_{2} \mathrm{O}_{3}$ and $\mathrm{SiO}_{2}$ particles, cross-linking agent and catalyst into Hydroxyl-terminated polydimethylsiloxane (used as matrix). The effect of micron solid particles and tensile speed on the mechanical property of micron particlesfilled silicone rubber was researched by uniaxial tensile test, and the following conclusions were obtained as follows:

The mechanical property of micron particles-filled silicone rubber is rate-dependent which is similar to the rubber-like material, and the property has a hyperelastic character. Thus, the silicone rubber belongs to the polymer materials that have both hyper-elastic and viscoelastic properties.

(b) The tensile strength of micron particles-filled silicone rubber increases with the content of the micron solid particles, but the elongation lack of the change rules due to the fact that lots of micron solid particles with high modulus are distributed in the silicone rubber matrix,. (AUTHOR: The highlighted is vague and must be re-phrased) The matrix was cut into many discontinuous matrix segments along the loading direction. the increase in the matrix segments resulted in increase in the materials' strength with the increase in solid particles' content;

(c) The rate-dependent mechanical property of micron particles-filled silicone rubber is mainly due to the property of matrix. Micron solid particles increased the modulus of the material and the instability of adhesive properties between micron solid particles and matrix, leading to large differences in the materials' elongation.

\section{CONFLICT OF INTEREST}

The authors confirm that this article content has no conflicts of interest.

\section{ACKNOWLEDGEMENTS}

This work was supported by Natural Science Foundation of Jiangsu Province (No. BK20140772), the Fundamental Research Funds for the Central Universities (No. 30915011301). We thank LetPub (www.letpub.com) for its linguistic assistance during the preparation of this manuscript.

\section{REFERENCES}

Chen G, Chang H. The research progress of silicone rubber coated layer. Chin J Energetic Mat 2005; 13(3): 200-03. 
[2] Zhang D. The Next Generation of Insulation polydimethylsiloxane. J Solid Rocket Technol 1993; 2: 011.

[3] Zhao F, Wang X. An Investigation of Mechanical Reinforcement of Silicone Inhibitors. J Propul Technol 1994; 4: 77-83.

[4] Kwan KS, Harrington DA, Moore PA, et al. Synthesis and use of colloidal silica for reinforcement in silicone elastomers. Rubber Chem Technol 2001; 74(4): 630-44.

[5] Meunier L, Chagnon G, Favier D, et al. Mechanical experimental characterization and numerical modelling of an unfilled silicone rubber. Polymer Testing 2008; 27(6): 765-77.

[6] Xu Q, Pang M, Zhu L, et al. Mechanical property of silicone rubber composed of diverse vinyl content silicone gums blending. Mat Design 2010; 31(9): 4083-87.

[7] Korochkina TV, Jewell EH, Claypole TC, et al. Experimental and numerical investigation into nonlinear deformation of silicone rubber pads during ink transfer process. Polymer Testing 2008; 27(6): 778-91.

[8] Zhou W, Qi S, et al. Al2O3 Effect on the Properties of Thermal Conductive Silicone Rubber. China Synthetic Fubber Industry 2006; 29(6): 462-65.

[9] Lin J, Feng Y, Qiu T. Preparation and Mechanical property of Modified Carbonyl Iron Powder/Silicone Rubber Composite. Aerospace Met Technol 2011; 41(3): 53-55.
[10] Zhou W, Qi S, Tu C, et al. Effect of the Particle Size of Al2O3on the Properties of Filled Heat-Conductive Silicone Rubber. J Appl Polymer Sci 2007; 104: 1312-18.

[11] Wang L, Ding T, Wang P. Effects of instantaneous compression pressure on electrical resistance of carbon black filled silicone rubber composite during compressive stress relaxation. Composit Sci Technol 2008; 68: 3448-50.

[12] Yoshimura K, Nakano K, Miyake T, et al. Effect of compressive and tensile strains on the electrical resistivity of carbon microcoil/silicone-rubber composites. Carbon 2007; 45: 1997-2003

[13] Sim LC, Lee CK, Ramanan SR, et al. Cure Characteristics, Mechanical and Thermal Properties of A12O3 and $\mathrm{ZnO}$ Reinforced Silicone Rubber. Polymer-Plastics Technol Eng 2006; 45: 301-07

[14] Sebnem K, Guralp O, Ayse A. Properties of thermally conductive micro and nano size boron nitride reinforced silicon rubber composites. Thermochimica Acta 2010; 499: 40-47

[15] Wang L, Ma F, Shi Q, et al. Study on compressive resistance creep and recovery of flexible pressure sensitive material based on carbon black filled silicone rubber composite. Sensors and Actuators A: Physical 2011; 165: 207-15

Received: May 15, 2015

Revised: June 23, 2015

Accepted: July 4, 2015

(C) Xiong et al.; Licensee Bentham Open.

This is an open access article licensed under the terms of the Creative Commons Attribution Non-Commercial License (http://creativecommons.org/licenses/ by-nc/4.0/) which permits unrestricted, non-commercial use, distribution and reproduction in any medium, provided the work is properly cited. 